\title{
Floods in Jeddah, Saudi Arabia: Unusual Phenomenon and Huge Losses. What Prognoses
}

\author{
Faouzi Ameur
}

King Abdel Aziz University, Faculty of Environmental Designs, Geomatics Department, Jeddah, Saudi Arabia

\begin{abstract}
Situated in the South-West of Saudi Arabia, Jeddah is the biggest port city in the red sea and the kingdom's second city after Riadth. Jeddah has a population of 3500000 inhabitants. It benefits from many economic assets due mainly to its being a transit point toward the holly sites of Islam. Despite being characterized by a dry climate, by poor rain fall levels, by deficits of rain compared to evaporation, and by the irregularity of water flow systems along with the functional degradation of its hydraulic networks, Jeddah underwent many unexpected floods- three big ones in 2009, 2010, and 2011. The human tolls as well as the material losses were huge: hundreds dead, thousands of damaged buildings which were built on slopes or close to river beds with legal permits. Such floods were studied by local and national authorities as well as scholars in order find adequate solutions.

It is within this framework and with modelization statistics and cartographic analyses in mind that we will attempt to understand what caused such floods:
\end{abstract}

-Natural causes (geo-morphological specifics, climate change, intensive rainfall),

- Human causes: lack of hazard culture, urban extension and planification, and the absence of viable strategies of prevention

\footnotetext{
${ }^{a}$ Corresponding author: faouzi@netcourrier.com
} 


\section{Introduction}

Saudi Arabia is located, according to Köppen world map classification [8], in a semi-arid weather zone. This zone is characterized by hot temperature and a rainfall which is inferior to evaporation. It rains mostly following short and intense storms in the western and south-western regions of the Kingdom where the city of Jeddah is located. The raining period extends from October to April and often times floods occur in urban and heavily populated places. Jeddah is one of these places [7].

Jeddah is the red sea's biggest port city (figure 1). It is also the second biggest city in Saudi Arabia. It has a population counting 3500000 . The city has economic assets due to its being a transit city to Islam holly cites: Mecca and Medina. During summer, Jeddah becomes a political and tourist city for Saudis. Despite being characterized by a dry climate with a low rate of precipitations, the city of Jeddah has witnessed sudden floods- three big floods in 2009, 2010, 2011. Human and economic losses were extremely important. These exceptional events, led local and national authorities, along with scholars and scientists, to focus on Jeddah's floods in order to find suitable solutions.

Figure 1: Location of Jeddah

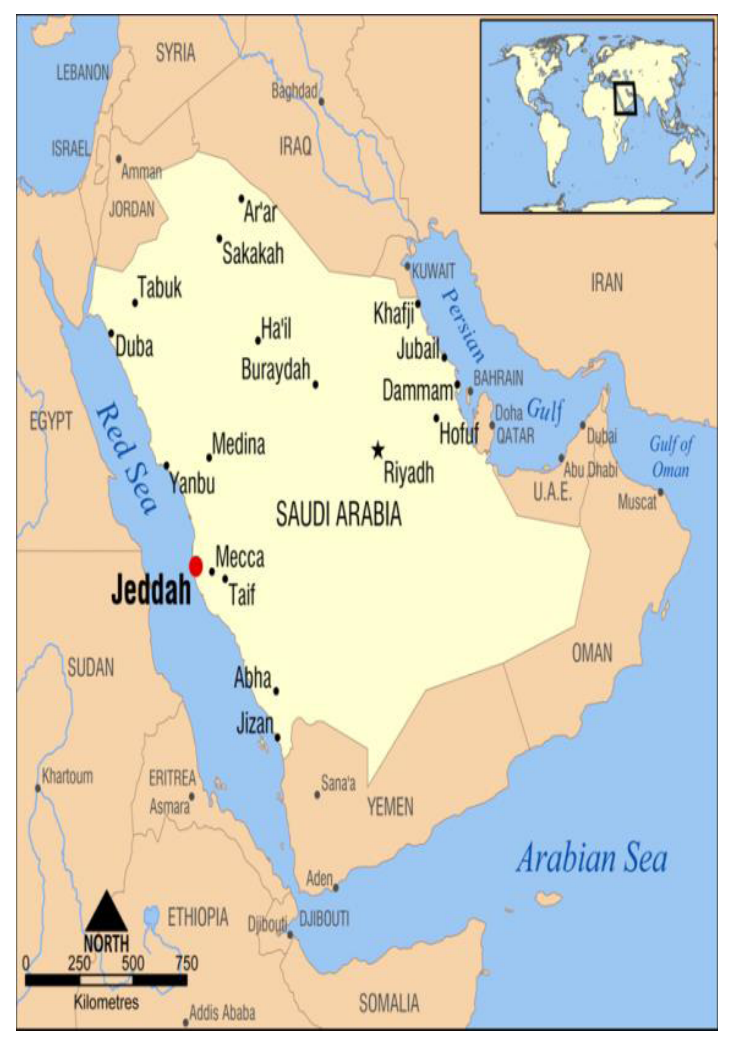

\section{General geology}

The study area constitutes a part of the western Arabian Shield [5], which is covered by Neoproterozoic rocks consisting of various types of volcanics and volcaniclastics, together with several varieties of intrusives (diorites, granodiorites and granites). These rocks are covered by Tertiary and Quaternary lavas and sediments and in places by recent sediments and sabkhas. Three distinct geologic units could be distinguished in the concerned area, these are from oldest to youngest [3] [6]:

- The Neoproterozoic rocks lie in the eastern part of the area, which is mostly covered by the Red Sea hills and pediments. They consist of volcanic rocks intruded by plutonic rocks (diorite and granite).

- The Tertiary rocks are present in the east of Jeddah city that includes Shumaysi, Usfan, and Hadat Ash-Sham formations which is covered by basaltic lavas.

- The Holocene unit includes the recently emerged marine deposits and corals. These rocks include the recent basaltic lava flows, the wadi alluvium, sabkha deposits, and the aeolian sands which are located along the coastal plain and pediments [18].

\section{Previous Studies}

Studies on floods in Jeddah city before 2009 were rare enough, and if they existed, they were merely part of more general studies that focused on broader environmental issues [14]. A unique study was carried out in 2009 and it focused on floods that occurred among a number of watersheds in the area located between Jeddah and Yanboua [1] [2]. If there were studies dedicated to flood assessment, they would be applied to the whole of Saudi Arabia.

Authors have given more attention to the topic of floods since the severe episode that took place in November 2009, and especially after another flood occurred in January 2011. Both events resulted in many casualties, and in damage that severely affected the infrastructure and inhabitants of Jeddah City and the surrounding areas. In this context, investigations were undertaken in order to understand the general conditions that gave rise to them, so that flood control measures could be taken in the region, and a number of preliminary reports and press releases were issued directly after the events. The author of this study is concerned with floods and torrents from the geomorphological and hydrological point of view, and has gathered information obtained using geomatics. 


\section{The consequences of flood}

\subsection{The history of floods in the City of Jeddah before 2009}

According Katibah Maghrabi [9], the main floods, which happened in Jeddah, are:

- The floods of 1968, which came from the valleys east of Jeddah and destroyed many constructions as well as the walls of the old airport. However, the built-up area was not as big as the current one.

- The flood of November 1972: the quantity of rain reached $83 \mathrm{~mm}$ in a short period of time and left its destructive action on the streets of the old districts and formed swamps, which polluted the environment

- Floods of 1979, which resulted from continuous rain. The water rose in the streets above 1 meter, life ceased for three days.

- Floods of November 1985, which happened after heavy rain over Jeddah and the surrounding area.

\subsection{The flood in 2009, 2010 and 2011}

Three major flash flood events occurred in Jeddah city during 25 November 2009, December 2010 and January 2011. These events were characterized by rainfall precipitation values of 70 and $111 \mathrm{~mm}$, respectively. Each flash flood event had duration of three hours [7]. With sound infrastructure and proper drainage systems, lacking, this rain turned into a worst disaster. The downpour resulted in water tides coming from the hills on the East of city, heading west to the red sea, and cutting their way through the city. Jeddah has rare rainfalls, and hence preparedness to any risk arising from such a natural phenomenon is, at best, minimal. The passage of the floods through a city with almost nonexistent drainage systems was devastating. Several residential houses collapsed. King Abdel Aziz hospital was affected by water waves. The hospital's underground was repeatedly reported to have been submerged with water. Laboratories and databases were destroyed, wasting valuable resources, specimen and medical records. Major roads of the city were blocked by metershigh water waves, or by cars that have been washed out [10].

As for the monetary losses, it amounted to about 1 billion dollars, long installations and government facilities and compensation for those affected was estimated at 2 billion dollars. As for the number of deaths it reached 122, according to Arab News [19] and to the statement of defense and civilian volunteer efforts accounted scene in Jeddah [20]. The Guardian [21] said hundreds had died in the Jeddah floods 2009. About 10 people also died in 2011 when additional floods swept through Jeddah. The number of those sheltered was about 26,711 people in furnished apartments and also pay subsistence for the families of 7821 people. 11849 damaged properties and 10913 damaged cars were estimated (figures 2, 3 and 4). Commercial traffic was paralyzed and sales fell to about $60 \%$ in some shops and the fear of epidemics and diseases (dengue fever) spread. What is more, the flood led to the destruction of farms along the road in length of about $100 \mathrm{~km}$. Some buildings got cracks such as residential buildings, shops, leading the collapse of some houses.

Figure 2: Jeddah's flood (January 2011)

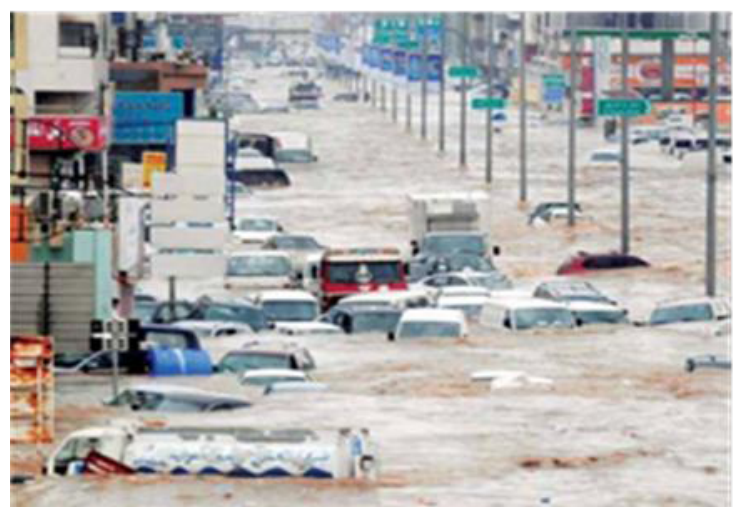

Figure 3: Tunnel in King Abdullah Street (December 2010)
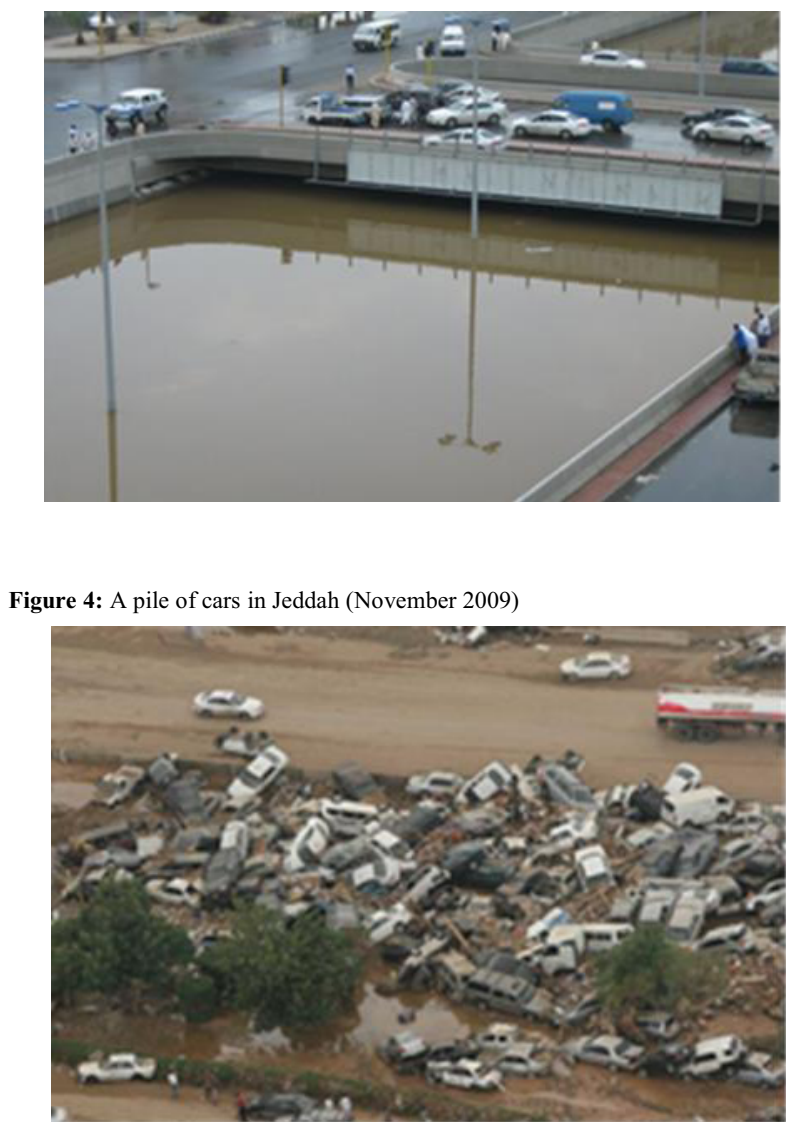


\section{Causes of flood in Jeddah 4.1 Rain Characteristics}

Figure 5: Annual office plurality of precipitations in the station of Jeddah

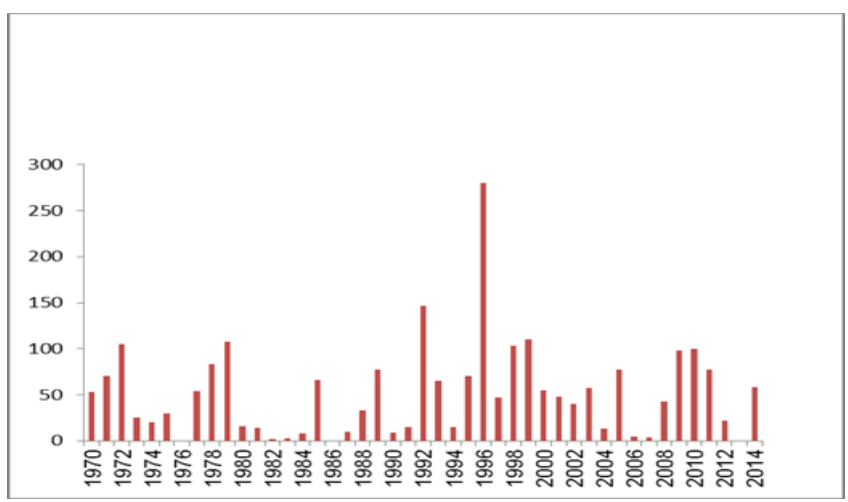

Source: Presidency of Meteorology and Environment (KSA)

Figure 6: Monthly precipitations in the station of Jeddah (1970-2014)

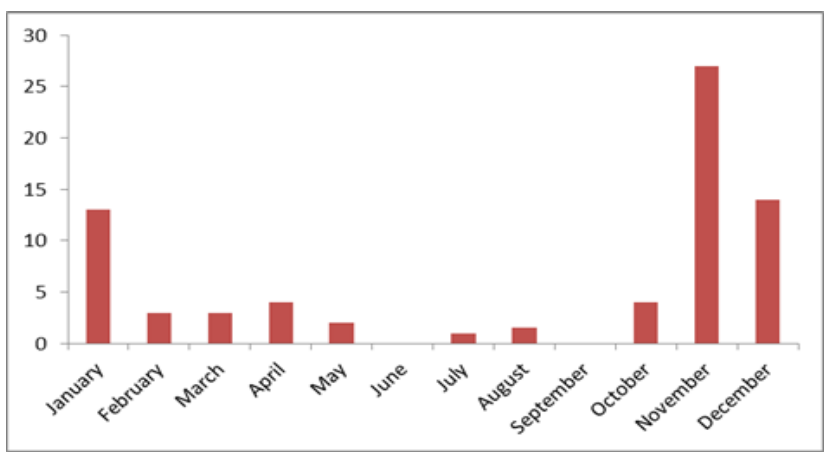

Source: Presidency of Meteorology and Environment (KSA)

It arises from figures 5 and 6 that the pluviometric mode of the zone of Jeddah is characterized by a great interannual variability marked by the alternation between wet years (like in 1996, year during which one recorded 284 $\mathrm{mm}$ ) and completely dry years as 1986 (where no drop of rain was recorded according to the treated data). As for the seasonal variation of the rains, one notes that precipitations occur in winter (they start in October and finish in April, figure 8). They are typical of the climate of temperate zones and Mediterranean characteristics. It is thus, not the mode of monsoon which is generally active in the month of July and September. One can also say that November records the maximum of precipitations and which the protection services civil must be more vigilant to envisage periods of raw wadis and floods. The analysis of precipitations day laborers (even if these last do not cover all the period) is interesting. It shows that, precipitations day laborers fallen during the flood of $2009(70 \mathrm{~mm})$ "Flash flood or believed flash" are most important since 1979 in 24:00. This extreme event combined with the urban growth that the city knew during this time, explains the gravity and the extent of the recorded catastrophes. The Seventies did not know major floods, in spite of great quantities of rain falls (1972, 1973.1978 and 1979), that is due to the absence of the urban development during this time in the zones at the risk (beds of the wadis). The year $1996 \mathrm{knew}$ an exceptional annual office plurality, but did not cause damages because the rains fell over several days [4] [7].

It clearly appears that Saudi Arabia is located in new climatic trends, represented mainly by torrential rains. That was obviously marked by events of frequent natural disasters and more especially of intense precipitations in the various parts of the territory. The catastrophes recorded in 2009 and 2011 are induced by problems of urbanization. The town of Jeddah does not have a truly effective system of cleansing and of drainage, especially the southern part of the city, the houses localized in the beds of the wadis and are badly built and do not respecting the technical standards. The recorded significant pluviometric events these last years and about which not much was said in the media are those of the month of January 2011 "75.9 mm", December 2010 “65.6 mm” and November 2009 "70 mm” (Figure 7)

Figure 7: Precipitation day laborers in the station of Jeddah (1970-2015)

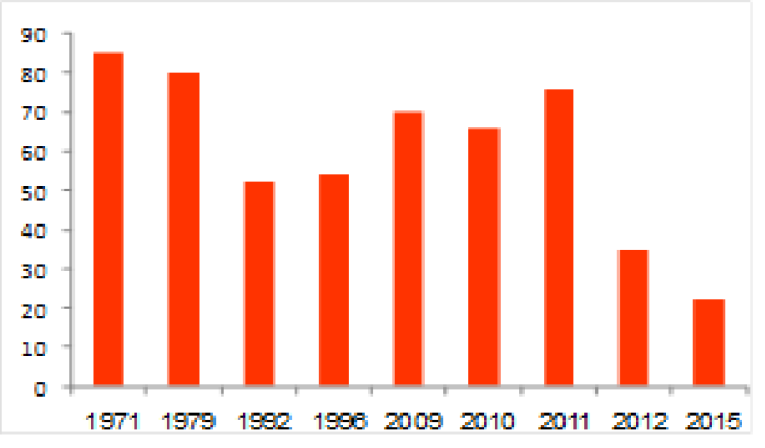

Source: Presidency of Meteorology and Environment (KSA)

\section{2 absence of a culture of risk}

According to UNESCO [23], "in its broadest direction culture can be regarded today as the whole of the distinctive features, spiritual and material, intellectual and emotional, which characterize a company or a social group. It includes moreover arts and the letters, the lifestyles, the basic rights of human being, the systems of values, the traditions and the beliefs". For Sandrine Glatron [22] "to mention the existence of a culture of the risks, it is to refer to a knowledge, a collective luggage common to all those which belong to a company: the members of this one would have a particular manner to conceive the risk" the term of risk appeared in Europe in a quite particular context, that of the rise of the big business towards Asia at the 13th century and the 14th century. In the same way the institutions of risk management are installation gradually [24]. In the field of risks generally and the risks hydrological in a particular way, the effectiveness of prevention passes by a training and information of the citizens to allow them to adopt a responsible behavior in all full knowledge of the facts. To identify the zones at the risks must be systematic and 
close to the knowledge of the public one. The population must be informed of the risks which it incurs.

In Jeddah and at the time of floods, one notes an absence of culture of risks among the citizens which appears as follows:

- A bad knowledge of the citizen of his environment.

- A bad knowledge of vulnerability.

- An absence of the reflex in time of danger.

- An absence of information on the risk which can exist on the territory.

At the time of an investigation into the perception of the risk of flood carried out in the district of Guiza in October 2015. 400 persons were asked the following question: Do you estimate to be quite informed about the flood risk? The result is the following: $93 \%$ of the surveyed people answered by not and the remaining 7\% did not answer the question (Figure 8). This underlines the absence of a culture of risk among inhabitants; the absence of conscience of the risk also appears among decision makers. After the flood events, a number of preliminary preventative measures were taken, but these were not based on solid scientific study of the matter, because such studies did not then exist. There was an urgent need to carry out a comprehensive assessment of the situation in order to avoid the recurrence of such catastrophic events.

Figure 8: Survey Results in the district of Guiza (October 2015)

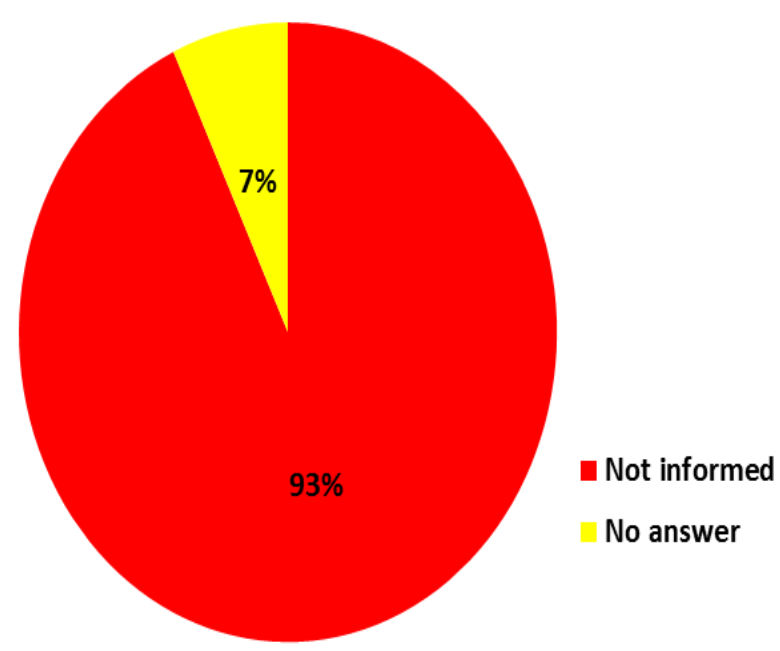

\section{Urban Expansion}

\subsection{The city is a place of danger}

The city was always exposed to dangers [11]. It is at this level that one could speak about urban risk. Until recently, three dangers were recurring at the point to be regarded as specific urban risks like fire, famine (or of the food shortages) and other epidemics. To these risks were added the flood and in a very specific way, the earthquakes (Lisbon in 1755) and volcanicity. Moreover, restricted dimensions of the majority of the urban organizations explain why the other great natural disasters (droughts, heat waves, hails, storms, etc.) were overlooked. Lastly, the city was the place of sporadic agitations: social riots, generally related to political crises, frumenties, riots. The riots frumenties could strongly destabilize the social and political body beyond the simple territorial limits of the city

With scientific progress, the old risks are gradually controlled [12]. The fire becomes little by little an accident. So certain risks as the health risks continue in the least favored layers of the population, one does not regard them any more as specific urban risks, apart from some pathologies like lead poisoning. On the other hand, new risks appear in connection with the new industrial functions of the city. The industrial risks become the urban danger par excellence. To look more closely at these dangers; they seem to be the fruit of progress technical and technological, the price to be culturally paid for the economic development and human whose contemporary city was the symbol a long time, in opposition to a campaign perceived like economically and late. But the question that needs to be asked is the following one: were these dangers specific to the city? One can identify three type of danger which is seen as being specifically urban:

- Technological risks

The technological risks and the industrial risks remain the urban risks par excellence.

- Health risks and environmental

Dependent on the urban lifestyles: pollution, rustled, stress, stress, degradation of the landscapes.

- Risks related to the fracture of the social body

They can be sporadic violence, which point out the urban riots of the past, crawling insecurity taking various forms and with the people), terrorist acts, etc.

It appears that these dangers are not specifically urban in a strict sense: there exist industries elsewhere than downtown. In the same way, the medical, environmental and societies dangers are not specific to the city. But they are associated with the urban environment insofar as it is there that they are expressed with the most intensity, where they create the more important disturbances, where the elements which give them rise are seen like specifically urban. In opposition to these dangers, the natural risk seems foreign to the city. It is the irruption of nature downtown, while at the same time the city is thought like wrenching of nature. 


\subsection{Increase of Urban Population}

\subsubsection{Increase of Urban Population in Saudi Arabia}

According to the United Nations "World Urbanization Prospects" [24], urbanization in Saudi Arabia is the world's most rapid. Urban population percentage was almost $20 \%$ in 1950 and will be nearly $90 \%$ in 2050 . Moreover, the urban population has increased from 665000 in 1950 to 24800000 in 2015. It will reach 35800000 in 2050 . This means that there will be an overall 11 million increase during the next 34 years. The urban increase will occur in metropolitan cities like Jeddah.

\subsubsection{Increase of Urban Population in Jeddah}

The population of Jeddah grew from an estimated 404,600 in 1971 to 595,900 in 1974 , and 915,800 in 1978; this gives an exponential growth rate of $11.3 \%$ between 1974 and 1978. Since then the Jeddah population has shown a steady increase until it reached 1,234,200 inhabitants in 1985 . In 2010 about 3500000 people live in Jeddah.

\subsection{Land management}

Studies on floods in Jeddah city before 2009 were rare enough, and if they existed, they were merely part of more general studies that focused on broader environmental issues [13] [14]. A unique study was carried out in 2009 and it focused on floods that occurred among a number of watersheds in the area located between Jeddah and Yanboua [2]. If there were studies dedicated to flood assessment, they would be applied to the whole of Saudi Arabia.

Risk (disaster) is an essential component of land management since danger is always there [25]. Urban land management actors set up measures to prevent predictable natural risks (disasters) like floods. These measures aim when necessary at:

- Identifying zones exposed to risks

- Identifying zones that are not directly exposed to risks

- Defining prevention measures to protect and safeguard risk zones

Urban management actors in Jeddah used many documents to put up with the city expansion: master plans, regional development plans, and structural local plans. Decisions were made to solve obvious problems like state buildings, city roads [15]. For years, city planners, urban managers, and public authorities neglected floods in all urban managements.

Nonetheless, Jeddah urban management was overseen by two ministries:

- The Ministry of municipal and rural affaires. This ministry looks after the physical development of the kingdom.

- The Ministry of Economy and Planning. Lack of coordination between these two ministries left, according to Daghesteni [16], local public authorities powerless and unable to carry out their duties properly.

\subsection{Urban Sprawl}

Figure 9: Jeddah's Urban Sprawl

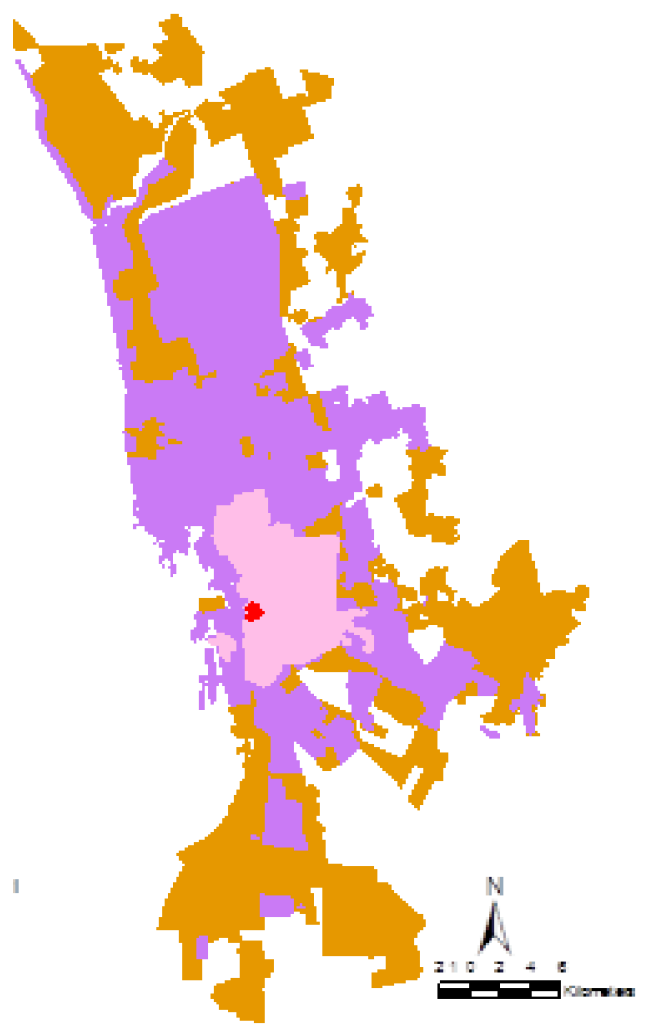

History of Jeddah's Urban Sprawl

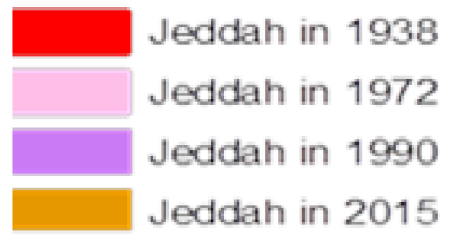

Jeddah was limited to the old city known as "Elbaled" (figure 10 and 11). The demolition of the walls of the ancient city in 1947 ushered in Jeddah's stretch process. From 1973 till present, the city northern and southwestern expansion continued to grow. It should be mentioned at this level that Jeddah's expansion was mainly to the North and occasionally in other directions.

Numerous investigations related to the floods of 2009 and 2011 show that:

- Urbanism has affected the water cycle and this obvious in terms of:

*Ground waterproof

The most obvious effect of urbanization is ground waterproof. This effect reduces water infiltration and this explains in huge measure how floods happen.

*The second most important effect of urbanizationthough less obvious but is nonetheless very important- is water drain.

- The construction of obstacles to water drainage. 
Urbanization even in pre-urban zones is accompanied by the construction of roads and streets.

Figure 10: Jeddah before the demolition of the walls

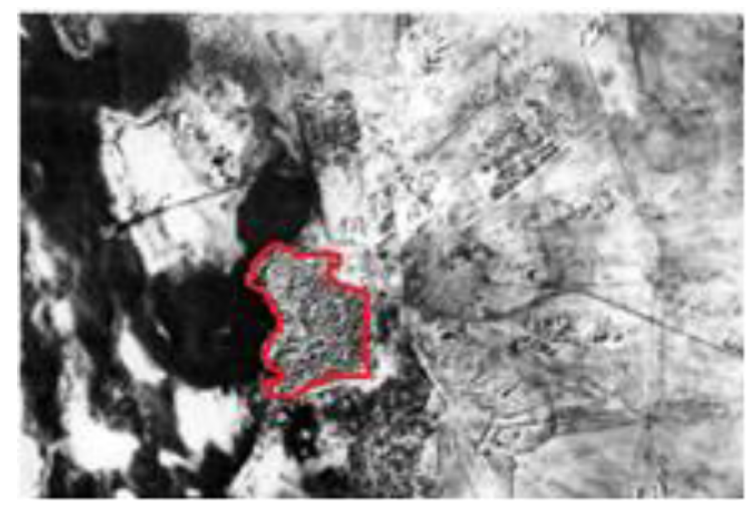

Source: Alharbi, T.H, 1989

Figure 11: Elbaled (old city)

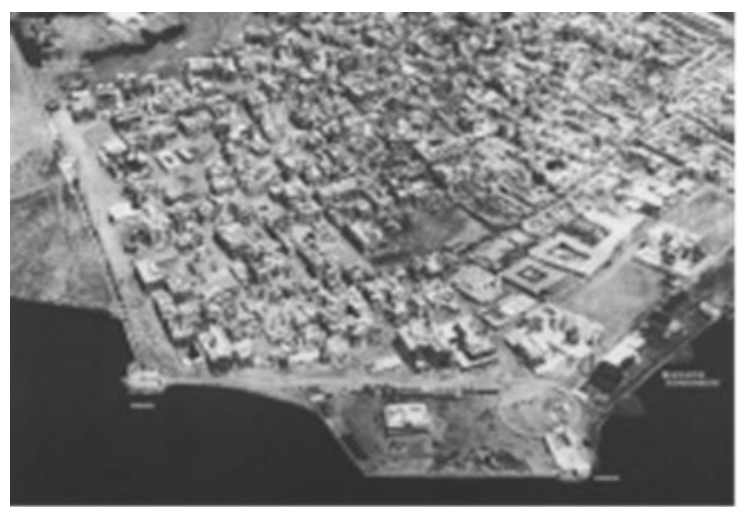

Source: Alharbi, T.H, 1989

\subsection{Geomorphological of Jeddah district}

features:

Jeddah region has different geomorphological

-The Red Sea shoreline: with an upper limit of $0.5 \mathrm{~m}$ of elevation. It has two distinct sub-zones or parts. The northern part is almost straight and is characterized by gently sloping and flat sand beaches, ridges, lagoons, sabkhas, and salt flats. The southern part is a huge complex concave bay named Jeddah Bay with open and closed lagoons. It has more than fifty islands and some of these islands display a variety of forms from linear to curved complex spits and atolls.

- The Coastal Plain Zone is approximately $10 \mathrm{~km}$ wide. It lies east of the red sea shore and extends in a N-NW direction. (Figure12). The coastal plain has an almost flat relief with gradient ranging between 0.002 at the northern part and 0.005 at the south of Makah road. The coastal plain area is characterized by coralline limestone, alluvial terraces, fluvial deposits, sabkhas, and Aeolian sands.

-The Coastal Hills and Pediments Zone extends roughly in a N-NW orientation. It lies east of the Red Sea coastal plain. It is made of low-lying hills which range in elevation between a few tens of meters in the West to a few hundred meters in the east above the sea line. Some characteristic features are present in this zone. Numerous peaks and hogbacks are present and they litter this zone at various locations.

Figure 12: Geomorphological Features of Jeddah

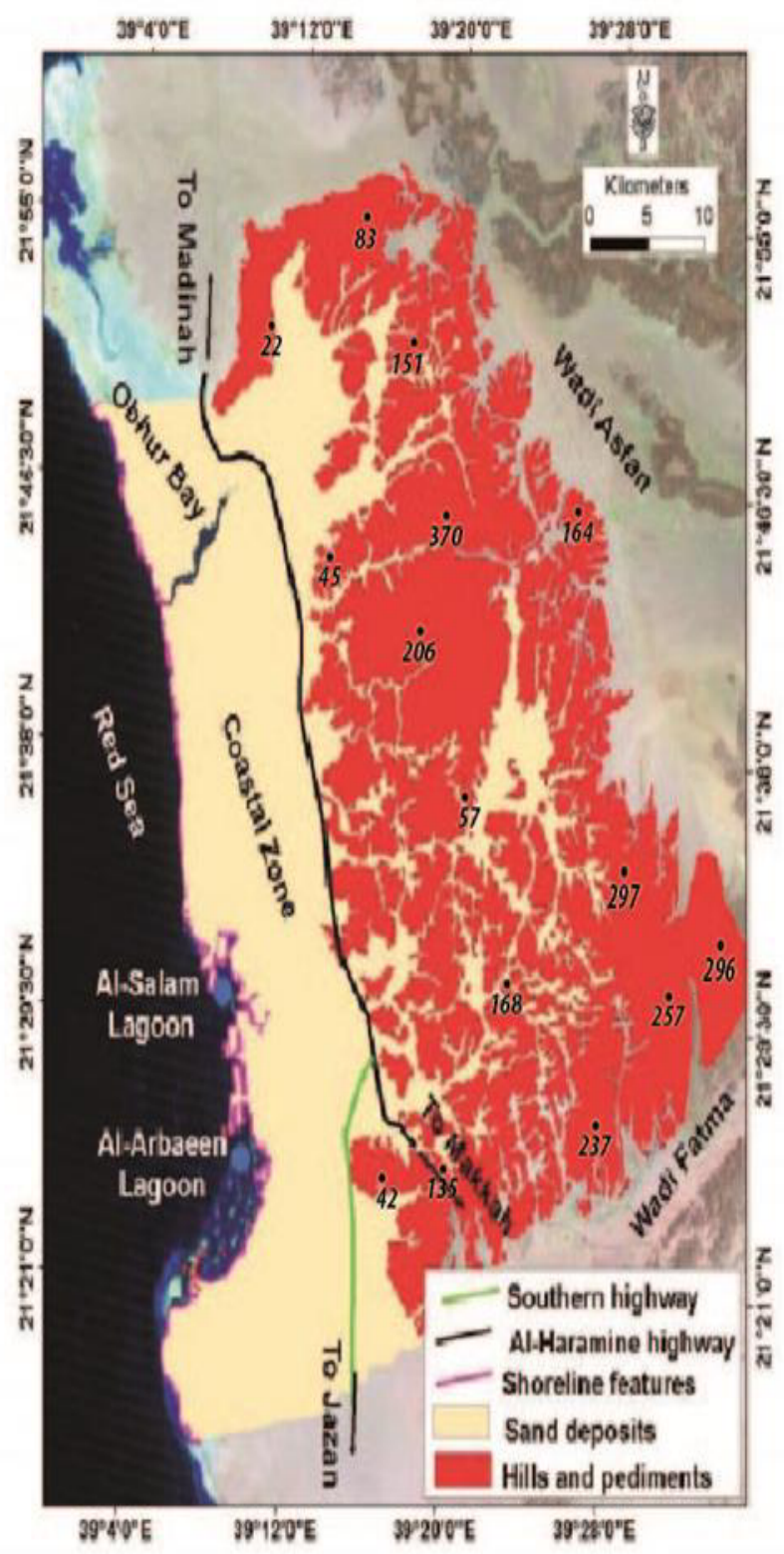

Source: Ahmed M.Y et al, 2015 


\subsection{Drainage Systems}

The classification and analysis of these systems involved descriptive and geometrical aspects. The description of the systems included distribution, location, extent or size, shape of catchment area, orientation, stage of development, genetic classification and the drainage patterns (figures 13, 14 and table 1).

\section{-Wadi Al-Kura}

This system is located at the northernmost part of Jeddah District. The system consists of numerous channels or subsystems that are separated from the main course of the Wadi. Owing to its extension through more than one geomorphological zone, the system shows more than one genetic characteristic; such as it is subsequent upstream in coastal hills along the coastal plain.

\section{-Wadi Muraygh and Wadi Ghuraiych}

These two wadis lie south of, and closet to, Wadi Al-Kura's system. Their upper courses exhibit a sudden and sharp shift in a N-S direction. The major wadi courses are directed toward the west. At their upper courses, they display trellis pattern. The lower courses of the wadi show parallel pattern, where the catchment area describes an elongate shape oriented in E-W direction.

\section{-Wadi Um Hadlayn}

This system is located to the North of KAA. It is formed of major channels. The main wadi channel terminates within the coastal plain at about $1.5 \mathrm{~km}$ from the sea shore.

\section{-Wadi Burayman}

It is located in the north of Jeddah city and consists of numerous curved short upper channels and double channels with a possibility of stream congestion at its middle course. The drainage density is high as it is heavily branched at the upper course than at the lower parts of the drainage basin and is moderate to high at the upper part within the coastal hills.

\section{-Wadi Hutayl}

This system is located in the northern part of Jeddah city. The drainage basin area is an elongated bananashaped within the main wadi and is directed toward the west.

\section{-Wadi Bani -Malek}

This is perhaps the most important system in the area in terms of length and basin area. The drainage branching ranges is very low in the western zone, moderate in the central zone, and low where the wadi might have once been either a continuation of the Wadi or another branch lying north of Wadi Mirayykh to the Red Sea.

\section{-Wadi Mirayyikh}

Is a relatively short system than the others in the area that lies south of Bani Malik and terminates at the central zone of Jeddah City. The drainage basin is relatively wider compared to its length. It differs also in this regard from the rest of the wadi systems in the area. The drainage density is very low in the western part and is moderate to high at the eastern part of the basin.

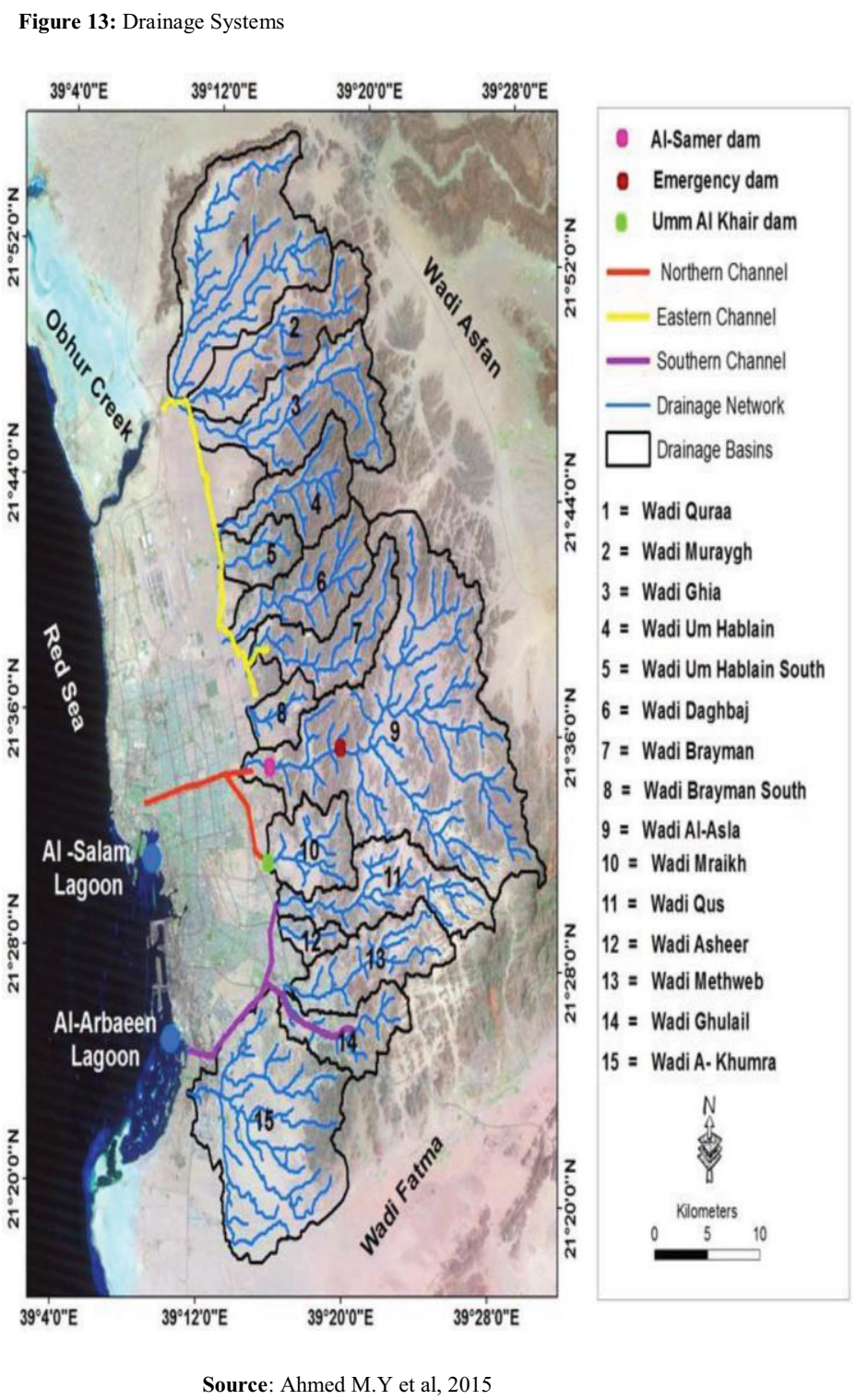


Figure 14: Classified Basin Types

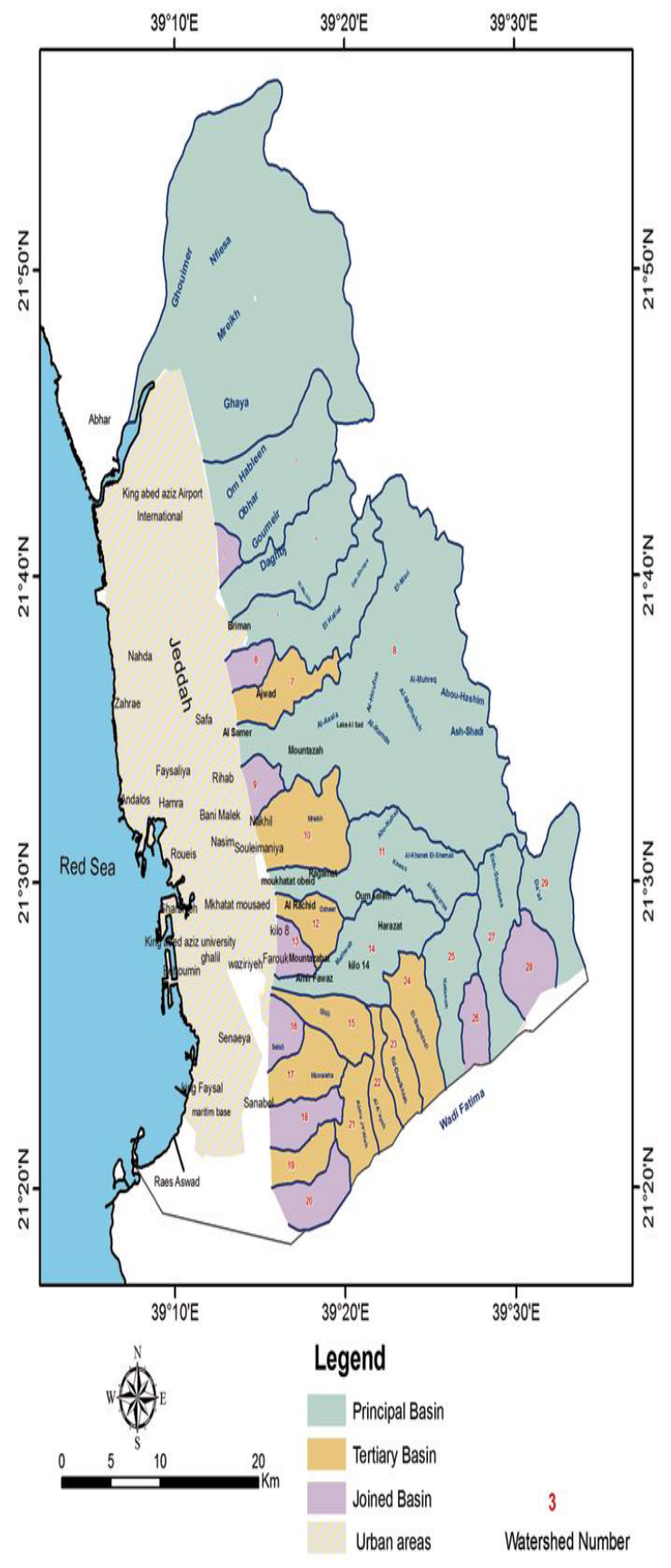

Source: Al Saud M, 2015

\section{Conclusion}

The risk of flood in Jeddah is a reality today that nobody can deny. Fast extension of urban fabrics as well as the absence of culture of risks among citizens and decision makers strongly increased the vulnerability of city to the risk of flood.

The present study of the risk of flood in Jeddah District, Saudi Arabia has made it possible to produce valuable data which can be developed and used within the framework of a geographical information system in order to set up a policy of natural risks management in Jeddah.
Table 1: Basins and their Streams

\begin{tabular}{|c|c|c|}
\hline No & Watershed & Area $\left(\mathrm{Km}^{2}\right)$ \\
\hline 1 & Ghouiemer & 319.7 \\
\hline 2 & Om Hableen & 75.7 \\
\hline 3 & Basin \# 3 & 6.5 \\
\hline 4 & Daghbj & 56.9 \\
\hline 5 & El Hatiel & 59.6 \\
\hline 6 & Basin \# 6 & 10.3 \\
\hline 7 & Basin \# 7 & 25.8 \\
\hline 8 & El Assla & 289.4 \\
\hline 9 & Basin \# 9 & 10.4 \\
\hline 10 & Mreikh & 46.7 \\
\hline 11 & Kawes & 70.1 \\
\hline 12 & Osheer & 17.7 \\
\hline 13 & Basin \# 13 & 12.5 \\
\hline 14 & Methweb & 54.2 \\
\hline 15 & Ghlil & 23.1 \\
\hline 16 & Selsli & 13.7 \\
\hline 17 & Muwaieha & 23.7 \\
\hline 18 & Basin \# 18 & 17.6 \\
\hline 19 & Basin \# 19 & 14.8 \\
\hline 20 & Basin \# 20 & 21.6 \\
\hline 21 & Abou Je'Alah & 21.2 \\
\hline 22 & Al A'ayah & 14.7 \\
\hline 23 & Ed-Dowikhlah & 17.1 \\
\hline 24 & El-Baghdadi & 29.6 \\
\hline 25 & Ketanah & 34.7 \\
\hline 26 & Basin \# 26 & 13.0 \\
\hline 27 & Esh-Shoabaa & 40.5 \\
\hline 28 & Basin \# 28 & 24.4 \\
\hline 29 & Da'af & 37.9 \\
\hline
\end{tabular}

Source: Source: Al Saud M, 2015 


\section{References}

[1] Subyani A (2010). Hydrologic behavior and flood probability for selected arid basins in Makkah area, western Saudi Arabia. Arabian Journal of Geosciences. DOI10.1007/s12517-009-0098-1

[2] Subyani, A.M, Qari, M.H., Matsah, M.E., AlModayan, A.A., and Al-Ahmadi, F.S. (2009). Utilizing remote sensing and GIS techniques to reduce hydrological and environmental hazards in some wadis, Western Saudi Arabia (Jeddah-Yanbu). King Abdulaziz City for Sciences and Technology, Project No. APR 25/101

[3] Qari M.H. (2009). Geomorphology of Jeddah Governate, with emphasis on drainage systems JKAU; Earth Sci., vol. 20, No. 1, pp 93-116.

[4] Subyani A.M, (2004). Geostatistical study of annual and seasonal mean rainfall patterns in southwest Saudi Arabia. Hydrological Sciences Journal vol. 49, No. 5, pp 803-817.

[5] Mohammed H.T. Qari (2009), Geomorphology of Jeddah Governate, with Emphasis on Drainage Systems, JKAU; Earth Sci., Vol. 20 No. 1, pp: 93-116 .

[6] Moore T.A., and Al-Rehaili, M.H. (1989) Geologic Map of the Makkah Quadrangle, sheet 21D, Kingdom of Saudi Arabia, Saudi Arabian Directorate General of Mineral Resources Geoscience Map GM-107C, scale $1: 250,000$.

[7] Ahmed M. Youssef, Saleh A. Sefry, Biswajeet Pradhan and Emad Abu Alfadail (2015): Analysis on causes of flash flood in Jeddah city (Kingdom of Saudi Arabia) of 2009 and2011 using multi-sensor remote sensing data and GIS, Geomatics, Natural Hazards and Risk, DOI: 10.1080/19475705.2015.1012750.

[8] Peel MC, Finlayson BL, and McMahon TA. (2007). Updated world map of the Köppen Geiger climate classification. Hydrology Earth Syst Sci. 11:1633 1644 [9] Maghrab K (2012), Impact of Flood Disaster on the Mental Health of Residents in the Eastern Region of Jeddah Governorate, 2010: A Study in Medical geography, Life Science Journal, vol. 9, No.1, pp.95-110. [10] Khan R (2013), Flood as a Disaster in the Middle East Region, International Journal of Scientific Engineering and Research (IJSER), Vol. 1, No. 3, pp 121-127.

[11] Abhas K Jha, Bloch R and Lamond, J (2012), Cities and Flooding: A Guide to Integrated Urban Flood Risk Management for the 21st Century, 638 pages

[12] Organisation for Economic Co-operation and Development (OECD) (2003), Emerging Systemic Risks in the 21 st Century, Paris, France, 290 pages

[13] Al Saud M (2010), Assessment of Flood Hazard of Jeddah Area 2009, Saudi Arabia, Journal of Water Resource and Protection, No 2, pp 839-847.

[14] Al Saud M (2015), Flood Control Management for the City and Surroundings of Jeddah, Saudi Arabia, The Springer Natural Hazards, 177 pages.
[15] Garba, S. B (2004). Managing urban growth and development in the Riyadh metropolitan area, Saudi Arabia Habitat International, 28, 593-608 http://dx.doi.org/10.1016/j.habitatint.2003.

[16] Daghistani, A. (1993). A case study in planning implementation. Working Paper No 32.

[17] Alharbi, T.H (1989). The development of housing in Jeddah : changes in built from the traditional to the modern, School of Architecture, University of Newcastle, England, 434 pages.

[18] Moore, T. A., Al-Rehaili, M.H. (1989). Explantory notes to the geologic map of the Makkah quadrangle, sheet21D, Kingdom of Saudi Arabia: Saudi Arabian Dir. Gen. Min. Res. Geoscience map GM-107C, 1:250,000 scale.

[19] Arab News (2012), Jeddah flooding to be a thing of the pas, http://www.arabnews.com/editorial-jeddahflooding-be-thing-past.

[20] Naill M, Momani and Ayman S. Fadi (2010), Changing Public Policy Due to Saudi City of Jeddah Flood Disaster, Journal of Social Sciences 6 (3), pp:424428.

[21] The Guardien (2009), Jeddah flood deaths shame Saudi royal, http://www.theguardian.com/commentisfree/2009/dec03/ Jeddah-floods-sewage-al-saud.

[22] GLATRON S, (2003), Culture des risques, V. Moriniaux (dir.), Questions de géographie: les risques, Éditions du Temps M, pp: 71-87.

[23] UNESCO (1982), World Conference on Cultural Policies, Mexico City, 6 August 1982.

[24] Meschinet de Richemond N. (2003), Statut et perception des catastrophes passées : vers une histoire géopolitique des risques naturels; V. Moriniaux (coord.), Les Risques, Nantes, Éd. du Temps, pp: 138-156 [25] United Nations, Department of Economic and Social Affairs, Population Division (2014), World Urbanization Prospects, 32 pages.

[26] Bucher S, Rode S (2009). L'aménagement des territoires face au risque d'inondation: regards croisés sur la Loire moyenne et le Val-de- Marne, M@ppemonde, N94(2-2009), http mappemonde.mgm./num22/ art09202.html. 